Earlier publications from the U.G.D.P. have provoked criticism of the selection of patients and the design of the trial. It has been claimed ${ }^{4}$ that $23.5 \%$ of the patients did not have diabetes, in $53.8 \%$ it was too mild to warrant drug treatment of any kind, while $50 \%$ of the patients were more than $33 \%$ overweight and should have been treated primarily by diet. What is more, $28 \%$ of the patients treated with phenformin and greater numbers in the other group did not follow their prescribed treatment. The comparability of the different treatment groups has also been questioned. Phenformintreated patients had slightly severer diabetes than the others, were equally overweight, and had slightly lower baseline blood pressures; $7 \cdot 4 \%$ gave a history of angina on entry into the trial, while $28 \cdot 2 \%$ were already hypertensive ( $>160 / 95 \mathrm{~mm}$ $\mathrm{Hg}$ ). In all groups fasting blood sugar fell on entering the trial with a gradual return to baseline by the last follow-up examination. Diet was clearly a key issue, for despite the large number of obese patients no treatment group showed a statistically significant weight loss beyond the second quarterly follow-up visit, by which time as little as $5 \%$ fall in weight had occurred. Clearly, therefore, the U.G.D.P. study is a far from ideal model from which to deduce the long-term effects of a drug which most physicians still regard as having a place in the management of diabetes.

The U.G.D.P. data showed a steady rise in supine systolic and diastolic blood pressure, which was confined to the phenformin group. There was no tendency to plateau and the rises amounted to $8 \%$ systolic and $4 \%$ diastolic at the five and a half year assessment. Interpretation of these findings is complicated by the high incidence of baseline hypertension and the effects of treatment. While $50 \%$ of normotensive patients became hypertensive on phenformin, so did $35 \%$ while on placebo; and while $40 \%$ of normotensive patients treated with phenformin received treatment for hypertension during the trial, yet so did $20 \%$ of those given insulin. This is a difficult background against which to judge the small mean changes in blood pressure noted for the phenformin group. Moreover, despite the fact that most deaths in the patients taking phenformin occurred in the newly hypertensive, the blood pressure findings for the deceased patients were similar to those of the entire treatment group.

Phenformin has several actions which are apparently unrelated to its hypoglycaemic effect; two of these have cardiovascular relevance. Firstly, it influences fat metabolism in diabetics, restoring the plasma free fatty acid (F.F.A.) turnover and triglyceride clearance towards normal, ${ }^{5}$ with associated falls in serum F.F.A., triglyceride, and cholesterol levels. ${ }^{6}$ Secondly, phenformin has a fibrinolytic effect, particularly when used in conjunction with an anabolic steroid such as ethylestrenol. ${ }^{6}$ This combination of drugs also reduces plasma fibrinogen and platelet stickiness. In individuals without electrocardiographic abnormalities reduced fibrinolysis is over three times as common in diabetics as in controls, while E.C.G. abnormalities are twice as common among patients with low fibrinolytic activity as among those in whom the tracing is normal. ${ }^{6}$ So there seems to be some case for using phenformin and ethylestrenol to combat the cardiovascular complications of diabetes.

Phenformin frequently causes side effects, and even pulmonary hypertension has been reported. ${ }^{7}$ There is, moreover, some supporting evidence for an increased incidence of myocardial infarction in diabetics treated with oral hypoglycaemic agents, ${ }^{8}$ though some workers ${ }^{9-11}$ have not found this effect even with phenformin. ${ }^{12}$ So it is still difficult to give clear guidelines on the role of phenformin in the management of diabetes, while for metformin (which is said ${ }^{13}$ to carry a reduced risk of lactic acidosis) even less information is available. Overweight adult-onset diabetics should ideally be treated by restriction of carbohydrate and calories, which can often return both the plasma glucose and the weight to normal; any other treatment must usually be regarded, at best, as an unsatisfactory alternative-though phenformin is frequently given to promote loss of weight. ${ }^{14}$ There is no good evidence to justify giving oral agents to patients on insulin, but the combined use of sustained action phenformin at a dose not exceeding $100 \mathrm{mg}$ daily and a sulphonylurea certainly appears to have a place in the management of a small group of patients who could not otherwise be controlled without insulin.

The latest U.G.D.P. report, while disquieting, must be weighed against the proved ability of phenformin to correct some of the metabolic abnormalities of adult-onset diabetes ${ }^{5}$ and the possible value of its fibrinolytic properties. ${ }^{6}$ For the time being the evidence against the drug is not strong enough to warrant abandoning its use in appropriate cases.

1 University Group Diabetes Program, Diabetes, 1975, 24, Suppl. 1.

2 Kannel, W. B., unpublished information.

${ }^{3}$ Knatterud, G. L., et al., fournal of the American Medical Association, 1971, 217, 777 .

${ }^{4}$ Moss, J. M., and DeWitt, E. DeL., Fournal of the American Geriatrics Society, 1973, 21, 72.

${ }^{5}$ Kissebah, A. H., Adams, P. W., and Wynn, V., Diabetologia, 1974, 10, 119.

6 Fearnley, G. R., Postgraduate Medical Fournal, 1969, 45 (Suppl. May), 52.

7 Fahlen, M., et al., British Heart fournal, 1973, 35, 824

${ }^{8}$ Boyle, D., et al., Lancet, 1972, 1, 338.

9 Drury, M. I., and Timoney, F. J., Acta Diabetologia Latina, 1972, 9, 645.

10 Keen, H., et al., Postgraduate Medical fournal, 1968, 44 (Suppl. Dec.), 960.

11 Paasikivi, J., Acta Medica Scandinavica, 1970, Suppl. no. 507.

12 Tzagournis, M., and Reynertson, R., Annals of Internal Medicine, 1972, 76, 587.

13 Vinik, A. I., and Jackson, W. P. U., South African Medical Fournal, 1974, 48, 2021.

14 Stowers, J. M., Clinics in Endocrinology and Metabolism, 1972, 1, 721.

15 Banerjee, R. N., et al., Diabetologia, 1975, 11, 105.

\section{Barbiturates On the Way Out}

Modern benzodiazepine drugs such as chlordiazepoxide are just as effective as the barbiturates in their therapeutic action, they have fewer side effects, they are not lethal in overdose, and their addictive potential is low. Yet social agencies and the police have no doubt about the source of the barbiturates that circulate among the young drug-addicts in the centres of our large cities : they come from the eight million or more prescriptions a year written for these out-dated ${ }^{1}$ drugs by N.H.S. doctors.

Against that background, the Campaign on the Use and Restriction of Barbiturates (C.U.R.B.) held a one-day course at the Royal College of Physicians in London last week to discuss practical aspects of the problem. C.U.R.B. was set up with Government support after the Advisory Council on the Misuse of Drugs had become alarmed at the growth of barbiturate abuse and the high morbidity and mortality found among young addicts using the drugs intravenously. Encouraged by the success of the voluntary control by the profession of the amphetamines, ${ }^{2}$ the members of C.U.R.B. believe that doctors can be persuaded to abandon the use of barbiturates voluntarily, ${ }^{3}$ so making unnecessary legal controls that might be resented as an infringement of clinical freedom. No one at the meeting had any doubts about the pharmacological case: barbiturates retain a place as induction agent ${ }_{s}$ 
in anaesthesia, and phenobarbitone will continue to be valuable in the control of epilepsy and a few other conditions such as hyperbilirubinaemia in infancy, but there are no circumstances in which hypnotics such as butobarbitone are the drugs of first choice.

But is addiction linked to faulty prescribing? How do the addicts get their supplies? Firstly, too many teenagers are introduced to barbiturates when they find them lying around the family medicine cupboard, unlocked and uncounted. Doctors and their patients have been too casual about these drugs for too long. Secondly, and more alarmingly, addicts get prescriptions directly from doctors' surgeries, either by stealing half-a-dozen E.C.10 blanks and forging them or by registering as a temporary resident and spinning a convincing yarn; when challenged they may threaten to cause a disturbance if sent away empty-handed. Doctors at the meeting with experience of this problem were unanimous on the need for firmness; one addict supplied will carry the news far and wide. Thirdly, they also get them from breaking into chemists' shops; experience has shown that in areas where doctors have learnt to do without barbiturates the pharmacists no longer stock them and the robberies cease.

Convincing as the case may be, there was a slight groundswell of doubt among some of the general practitioners present. What about their middle-aged and elderly patients who have for years been on a fixed dose of barbiturates as a hypnotic; would not switching them to a benzodiazepine be meddlesome, cruel, and arrogant? Again the answer came from those who had tried it. Broken sleep is a normal feature of ageing, and if reassured about it most old people will accept that fact. Regular barbiturate-users can be weaned on to an alternative easily enough if they are told why (the newer drugs are safer and less habit forming) and the changeover is gradual (spread over 6-13 weeks, one tablet at a time). More important, a substantial proportion of such patients find they can do without sleeping pills altogether-and feel much less muzzy during the day as a result. Compassion may be misplaced in those circumstances; the harsh fact is, the conference was told, that old age pensioners can and do sell their barbiturates to teenage addicts at $25 \mathrm{p}$ for a single capsule.

If, however, barbiturates are phased out, will not the whole cycle be repeated in a few years' time with the benzodiazepines, already shown in North America to be capable of abuse? The answer is probably not. Part of the C.U.R.B. campaign is directed at improving the therapeutic approach of doctors when treating patients with insomnia; the patient's expectation may be sleeping pills but a prescription should not be the doctor's automatic response. Better therapeutics should lead to fewer prescriptions and less reliance by society on drugs as solutions to its problems. Sadly, the second reason for doubting that the benzodiazepines would be the next problem in the drug scene is a realistic assessment of current trends. The opinion of the experts at the C.U.R.B. meeting was that the looming menace for the young generation is alcohol.

\footnotetext{
1 British Medical fournal, 1974, 4, 552.

2 Wells, F. O., British Medical fournal, 1970, 2, 361.

3 British Medical fournal, 1975, 3, 285.
}

\section{New Contract Priced}

A pay award which robs Peter to pay Paul would normally be greeted with derision. Why then has the B.M.A. reacted so calmly (p. 783) to the Review Body's recommendations (p. 784) pricing the junior doctors' new contract which do just this? There are several reasons.

Firstly, pricing is only one aspect of the contract which should improve substantially junior doctors' terms of service. ${ }^{1}$ Secondly, the Review Body has demonstrated that many juniors are still working long hours-too many, too often, too long - and that its aim is to reduce this work load. Thirdly, the working week for which the basic salary is paid has been reduced to a level that is appropriate to the 1970s. Fourthly, Sir Ernest Woodroofe and his colleagues have accepted the profession's suggestion, with modifications, that will equate salary supplements-which supersede extra duty allowances-with the work actually done, thus remedying the weaknesses of the present scheme whereby extra duty allowances did not start until 80 hours had been worked and which were the same whether the doctor was on call or on duty. Fifthly, though some junior doctors will lose some allowances (and probably many of these were paid for being on call rather than on duty) more will gain them, and because the new personal contracts will specify the work content of a post juniors will be able to forecast reliably their overall annual income, an advantage when seeking a mortgage. Finally, given the constraints of the Government's "voluntary" pay policy," redistribution in some form is inevitable and the Review Body has probably achieved this in the most constructive manner possible, while promising a further review in April 1976.

The report has also done a service for doctors by emphasizing the professional nature of the young doctors' work and rejecting the idea of premium payments for out-of-hours work. Junior doctors who criticized the new contract were particularly worried about the dangers to their professional status and this declaration may help to allay their fears. But those who have developed an affection for the open-ended contract as a safeguard for their professional status should recall that hospital authorities have for far too long been willing to exploit it so that many junior staff were seriously overworked. One of the main objectives of introducing extra duty allowances and of their refinement into this new contract was to reduce the over-long hours by making the N.H.S. pay heavily for them.

As the Review Body reminds us, medicine is not a nine to five occupation. Few doctors would be in it if it was and young doctors in particular expect to be busy. So, contrary to the current myth that in future junior staff will be working only a 40-hour week, they are quite willing to contract for reasonable extra duty time and to be available for the unexpected emergencies which, after all, form such a basic and challenging part of practice.

There have been calls for a ballot of junior staff before any new contract is settled. When the B.M.A.'s Hospital Junior Staffs Committee meets on 2 October to decide the profession's attitude to the award it will no doubt consider this suggestion. But a meaningful ballot requires an informed electorate. Recent correspondence and reported experiences of local meetings of junior staff suggest that many young doctors have not understood the new contract. So it is especially important that as many of them as possible attend the meetings being arranged in the regions by the B.M.A. Informed discussion at well-attended gatherings will be invaluable to the members of the H.J.S. Committee in making up their minds.

\footnotetext{
${ }^{1}$ British Medical fournal, 1975, 3, 398.

2 Remuneration, Charges and Grants Act 1975. London, H.M.S.O., 1975.
} 